\title{
Alkaline Anion Exchange Membrane Degradation as a Function of Humidity Measured using the Quartz Crystal Microbalance
}

\author{
V. J. Bharath ${ }^{a}$, R. Jervis ${ }^{a}$, J. Millichamp ${ }^{a}$, T. P. Neville ${ }^{a, b}$, T. Mason ${ }^{a}$, B. Tjaden ${ }^{a}$, P.R. \\ Shearing ${ }^{a}$, R. J. C Brown ${ }^{c}$, G. Manos ${ }^{a}$, D. J. L. Brett ${ }^{\text {** }}$ \\ ${ }^{a}$ Electrochemical Innovation Lab, Department of Chemical Engineering, University College \\ London, Torrington Place, London, WC1E 7JE, UK \\ ${ }^{b}$ Centre for Nature Inspired Engineering, University College London, Torrington Place, \\ London, WC1E 7JE, UK \\ ${ }^{c}$ Environmental Division, National Physical Laboratory, Teddington, Middlesex, UK, TW11 \\ OLW
}

*Corresponding Author

e-mail: d.brett@ucl.ac.uk

Tel: $+44(0) 207693310$

\begin{abstract}
The solid polymer electrolyte (SPE) alkaline anion exchange membrane (AAEM) fuel cell exhibits facile oxygen reduction reaction (ORR) kinetics and has the ability to utilise nonprecious metal electrocatalysts. However, the AAEM is reported to suffer from increased instability within the alkaline media (degradation) via a number of routes, including nucleophilic elimination when operated at temperatures above $60^{\circ} \mathrm{C}$, somewhat eliminating the kinetic advantage of operating at higher temperatures. Nonetheless, modelling studies have indicated that the membrane hydration could show improved resistance to alkaline instability and subsequent degradation when operated at elevated temperatures. This investigation uses the quartz crystal microbalance (QCM) to examine the thermal stability of a commercial AAEM as a function of humidity. The results show that hydration improves ionomer resistance to degradation, as the ions within the system (namely the $\mathrm{OH}^{-}$nucleophile and cationic headgroups) become less reactive. In-line mass spectrometry data confirms that the ionomer degrades during the elevated temperature excursions used in this study.
\end{abstract}

Keywords: Fuel cells; Hofmann Elimination; QCM; in-situ degradation; thin film. 
Alkaline anion exchange membrane (AAEM) fuel cells have the potential to replace the traditional acidic proton exchange membrane (PEM) fuel cells for low temperature applications. With more facile oxygen reduction reaction (ORR) kinetics than traditional PEM fuel cells, the alkaline medium allows implementation of lower cost, non-precious metal electrocatalysts [1, 2], compared to the more resilient precious metals (e.g. $\mathrm{Pt}$ ) required in acidic media [3-5].

AAEMs contain positively charged (cationic) headgroups that have been suggested to dissociate more weakly than the sulphonic acid groups found in Nafion; coupled with the inherently lower electrochemical mobility of $\mathrm{OH}^{-}$ions compared to protons, means that AAEMs typically have ionic conductivities approximately a quarter of those for PEMs [6]. Many AAEMs include more cationic groups along the polymer backbone to improve ion exchange capacity (IEC) and thus the ionic conductivity; however, the increased fixed charge concentration can lead to deterioration of the AAEMs' mechanical properties [7-9].

The most common cationic group in AAEMs is quaternary ammonium, $\left[\mathrm{R}_{4} \mathrm{~N}^{+}\right]$[10], which is often used as it has higher stability within alkaline media compared to phosphonium or sulphonium groups [11]. However, it has been well documented that AAEMs can also suffer from chemical instability in alkaline environments [11-13], with chemical degradation stemming largely from nucleophilic attack by hydroxide ions on the cationic fixed charged sites; a process accelerated by operation at elevated temperatures.

For example, the quaternary ammonium group is susceptible to cleavage in the presence of hydroxide ions, leading to the E2 elimination reaction (the Hofmann elimination) shown in Figure 1.

During E2 elimination, hydroxyl ions attack $\beta$-hydrogens, leading to the formation of an alkene, an amine and a water molecule. Most work to date has suggested that Hofmann elimination is negligible below $60^{\circ} \mathrm{C}$, but much faster at higher temperatures, resulting in significant membrane degradation [14-16]. This is an obvious limitation for current alkaline membranes as the kinetic benefit of operating at higher temperatures is unobtainable.

The other key mode of ionomer degradation is direct nucleophilic displacement at the cation site; this can occur through two possible reaction pathways for quaternary ammonium charge sites, as shown below in Figures 2 and 3. In these cases, the hydroxide ions attack at either 
the methyl group, forming methanol, or at the $\mathrm{C}-\mathrm{C}$ bond between the alpha and beta carbons to cleave the cation site ( $S_{N} 2$ reaction) [12]. These mechanisms are further discussed elsewhere [17, 18]. Other degradation routes presented within the literature include deprotonation of the $\left[\mathrm{R}_{4} \mathrm{~N}^{+}\right]$headgroups to produce nitrogen ylide intermediaries $[19,20]$ and specific studies on the degradation of the polymer backbone put forward by Arges et al. [21, 22], Chen and Hickner [23] and Mohanty et al. [24]. The consequence of these degradation mechanisms is a loss in the number of ion-exchange groups and a subsequent decrease in $\mathrm{OH}^{-}$conductivity, with consequences for fuel cell performance.

As with most SPEs, AAEM hydroxyl conduction improves with hydration as the ionomer channels solvate and subsequently swell $[25,26]$. There is a balance between improved membrane conductivity through hydration and the deleterious effects on performance seen in fuel cells caused by the formation of liquid water blocking reactant channels and gas diffusion layer pores. Recent published work [17, 20,27] on formulated head groups has added a new dynamic to this balance, indicating a correlation between ion solvation (and hence ionomer hydration) and ionomer degradation by nucleophilic attack.

The model presented by Chempath et al. [17] implements an untethered cationic head group, $\left[\mathrm{N}\left(\mathrm{CH}_{3}\right)_{4}\right]^{+}$, and shows that the degradation mechanisms appear more aggressive in a system with low water content. Work by Macomber et al. [20] reports a similar conclusion, where the thermal degradation of tetramethyl ammonium hydroxide is retarded by hydration. In both cases, the investigations explain that a dehydrated membrane exhibits more aggressive degradation, as both the hydroxyl ions and cations remain un-solvated and thus more reactive $[17,20]$.

This investigation experimentally explores how specific hydration levels affect the alkaline instability and hence degradation mechanisms of a commercially available AAEM ionomer (Tokuyama, Japan) with tethered quaternary ammonium headgroups, using a quartz crystal microbalance (QCM). The QCM has proved to be a powerful in-situ mass monitoring technique for the study of polymer interactions at a solid interface, offering nanogram mass resolution [28-31]. In-line mass spectrometry is used alongside the QCM in this study to further elucidate the importance (and limitations) of cation and hydroxide ion solvation for the stability of an AAEM ionomer. 


\section{Experimental}

\subsection{Quartz Crystal Microbalance}

The QCM is a bulk acoustic wave (BAW) resonator that is often used as an in-situ mass monitoring device with nanogram resolution [32, 33]. With an applied voltage, the QCM oscillates at a specific frequency as a function of its dimensions and the amount of mass deposited on its electrodes. If the system under consideration undergoes a mass deposition or loss, the shift in frequency can be accurately measured and the analogous contacting mass change can be determined using the Sauerbrey equation:

$$
\Delta f=\frac{-2 f_{o}^{2} \Delta m}{A \sqrt{\mu_{q} \rho_{q}}}
$$

Where $\Delta f$ is the measured frequency shift, $f_{0}$ is the microbalance's fundamental frequency, $A$ is the piezoelectric area, $\mu_{q}$ and $\rho_{q}$ are the shear modulus and density of quartz respectively, and $\Delta m$ is the corresponding mass change.

Aspects of the use of the Sauerbrey equation are well established and the reader is directed to [32-34] for further information. Studies often only consider the frequency shift of the QCM, limiting the extent of information accessible using the technique. Additional insight can be derived about viscoelastic changes in thin films by using crystal admittance spectroscopy (CAS). In the conventional (active) mode of operation, the QCM oscillates at its natural frequency and the Sauerbrey equation is used to provide a method of measuring mass change on the crystal surface. However, in complex systems, the frequency response can also be a function of the viscoelastic properties of the deposited material and the surrounding environment [35]. To better understand the acoustic coupling of the crystal with a deposited layer (composite resonator) and the surrounding environment, CAS (passive QCM operation) can be used to drive the frequency of oscillation across the resonance region [32, 36, 37].

CAS is described in detail elsewhere and the reader is directed to these sources for a more comprehensive guide [32, 36]. CAS is used in this investigation alongside equivalent circuit analysis (i.e. the modified Butterworth Van Dyke equivalent circuit, Figure 4) $[25,36,38]$ to monitor the changes in the viscoelastic properties of deposited layers during operation and to further classify the findings seen using the active oscillation methods. 


\section{2 lonomer Casting}

AAEMs based on $\left[\mathrm{R}_{4} \mathrm{~N}^{+}\right]$are known to form carbonates in the presence of $\mathrm{CO}_{2}$ (even at low concentrations) [39-41] and thus the experimental set up was developed to preclude any $\mathrm{CO}_{2}$ entering the system before and during ionomer casting and operation. The experimental setup is shown in Figure 5 and a further explanation is available in other work published by the authors [25].

The commercially available ( $\mathrm{OH}^{-}$conducting) AS-4 ionomer dispersion (Tokuyama, Japan) is cast in-situ under a $100 \mathrm{ml} \mathrm{min}^{-1}$ stream of dry nitrogen (BOC, UK) directly onto a $6 \mathrm{MHz}, 14$ $\mathrm{mm}$, gold coated double-anchor top electrode QCM (Inficon) using a micro-pipette. The casting process for each experimental run is conducted at $0 \%$ relative humidity $(\mathrm{RH})$ to eliminate the water content contribution to the ionomer thickness calculations. The composite resonator is then held at $55^{\circ} \mathrm{C}$ for 1 hour to allow the suspending IPA solution to evaporate and the ionomer to anneal.

The ionomer thickness is subsequently determined using the Sauerbrey Equation (1) and Equation 2 below:

$$
t_{i}=\frac{m_{i}}{A \rho_{i}}
$$

Where $t_{\mathrm{i}}$ is the ionomer thickness, $m_{i}$ is the ionomer mass (determined from the Sauerbrey equation), $A$ is the cast area and $\rho_{i}$ the density of the recast ionomer.

This investigation uses cast thin film $(100 \pm 4 \mathrm{~nm})$ ionomers for all studies to ensure that the cast mass is within the QCM's operable range [30], as well as to minimise erroneous levels of internal water diffusion contribution from the bulk when operating through the investigative range of relative humidities [29, 42,43$]$.

\subsection{Composite resonator operation}

During this investigation, the resonator is initially actively oscillated during the casting process to determine the ionomer thickness, as described; it is subsequently passively oscillated for the rest of the investigation to determine the effect of operation at elevated temperatures through a range of relative humidities. 
After annealing, the composite resonator is passively operated at $55^{\circ} \mathrm{C}$ (at a specific relative humidity) until it attains a stable frequency. The operating temperature is then ramped and held at $65^{\circ} \mathrm{C}$ for $45 \mathrm{mins}$, it is then cooled back to $55^{\circ} \mathrm{C}$. This investigation is repeated through a range of relative humidities with a freshly cast $100 \mathrm{~nm}$ composite resonator for each run. CAS data is recorded before and after the microbalance temperature ramp and the corresponding frequency shift is measured. Equivalent circuit fitting (Figure 4) is used to find the change in resonant frequency.

This investigation focuses primarily on determining a relative shift in the system's viscoelasticity during operation. As shown in Figure 4, the viscoelastic component can be represented by fitting the $L_{2}$ and $R_{2}$ terms; however, for simplicity of fitting and comparison, the $L_{1}$ and $L_{2}$ terms are frequently combined and the $R_{2}$ value (representing the power dissipation from the QCM surface into the contacting media) can be used to represent the relative shift in the composite resonator's viscoelastic properties [25, 32, 36].

The apparatus and rig design used throughout this investigation is shown in Figure 5, as described previously [25]. The system has been extensively tested and modified to minimise the effect of static capacitance - present in all systems from the resonator holder. Active oscillation measurements, in which the composite resonator's frequency response is measured when operated at a specific voltage, were carried out using a QCM analogue controller (QCM200, Stanford Research Systems, USA). The admittance or passive response is achieved using a Solartron 1260A impedance / gain phase analyser.

An in-line mass spectrometer (Hiden, UK) was used to analyse the components of the exhaust gas exiting the humidification chamber, to evaluate the extent of thermal degradation occurring. 


\section{Results and Discussion}

Figure 6 shows admittance data from the water uptake of a Tokuyama drop-cast ionomer operating through a range of relative humidities; the figure is adapted from a previous investigation presented by the authors [25]. The inset figure gives the admittance Bode plot showing the shift in series resonant frequency $\left(\Delta f_{s}\right)$ with increasing relative humidity. The observed trend exhibits two regimes of operation and has been attributed to distinct water uptake mechanisms; the first occurring between $0-65 \%$ relative humidity where the ionomer adsorbs water molecules that are used primarily for ionomer solvation, followed by a region between $65-100 \% \mathrm{RH}$ in which the adsorbed water acts to swell the previously solvated ionomer channels [25].

The following investigation compares the ionomer degradation and solvation using the QCM, CAS and mass spectrometry.

The admittance data for the composite resonator operating at $55^{\circ} \mathrm{C}$ before and after the rise in operating temperature (to $65^{\circ} \mathrm{C}$ for $45 \mathrm{mins}$ ) were recorded and fitted using the equivalent circuit shown in Figure 4. The system's viscoelasticity is represented by the $R_{2}$ term in the equivalent circuit [25, 30,32], and is the main component of interest in this study. The relative difference in viscoelasticity can be represented by the shift in $R_{2}$. The percentage change in $R_{2}$ before and after composite resonator operation at elevated temperatures for a range of relative humidities is shown in Figure 7.

Each data point shown in Figure 7 is conducted with a freshly cast composite resonator at a specific $\mathrm{RH}$; consequently, there is no additional hydration contribution to the composite resonator's viscoelasticity. This allows the percentage shifts in $R_{2}$ to be directly related to the composite resonator's viscoelasticity and subsequently to the processes occurring on the ionomer.

It can be seen that in general (initially excluding the $-\% \Delta R_{2}$ shift at $0 \% \mathrm{RH}$ ), as the relative humidity increases, the shift in the viscoelasticity of the ionomer layer, represented by the \% change in $R_{2}$, increases from $-11.2 \%$ at $11 \% \mathrm{RH}$ to $-4.2 \%$ at $88 \% \mathrm{RH}$.

Comparing the observed trend in Figure 7, with the water uptake mechanism data presented in Figure 6 , it can be seen that the $-\% \Delta R_{2}$ shift is most significant during ionomer solvation, i.e. between $11 \%$ and $66 \% \mathrm{RH}$. Below $66 \% \mathrm{RH}$, the ionomer is only partially solvating, the 
$\mathrm{OH}^{-}$ions and the cationic headgroups are more reactive and thus aggressive degradation can occur [20].

In the second water loading mechanism (above $\sim 65 \% \mathrm{RH}$ ) in Figure 6 , where the ionomer is fully solvated and undergoing swelling, the corresponding ionomer's $-\% \Delta R_{2}$ is significantly lower. This suggests that as the ions within the ionomer solvate, the degradation reaction becomes less aggressive. Between $66 \%$ and $88 \% \mathrm{RH}$, a constant shift in $-\% \Delta R_{2}$ is recorded, and correlates with the fact that the ionomer is fully solvated and in the swelling regime [25].

The experimental observations shown here support the computational and experimental theories proposed by Chempath et al. [17] and Macomber et al. [20] respectively (albeit for different systems), showing that hydration does indeed improve the ionomer's resistance to degradation at elevated temperatures.

At $0 \% \mathrm{RH},-\% \Delta R_{2}$ changes by only $5.1 \%$ (Figure 7 ). This is likely to be due to 'collapsed' ionomer channels (similar to that of Nafion); and only through hydration of the channels can they expand and allow the movement of $\mathrm{OH}^{-}$ions to the cationic head groups [44]. Thus, at $0 \% \mathrm{RH}$ the channels impede access of $\mathrm{OH}^{-}$ions, which results in minimal membrane degradation (and viscoelastic change associated with the shift in $R_{2}$ ).

Whilst the QCM is able to provide useful insight into what is happening at the interfacial level of the ionomer, it does not provide chemical information on the degradation process. By applying in-line mass spectrometry to the humidification chamber exhaust, it is possible to distinguish between regimes of membrane degradation and stability.

The mass spectrum shown in Figure $8 \mathrm{a}$ and the inset represent the system when the composite resonator is operating at $55^{\circ} \mathrm{C}$ under a dry flow of nitrogen. This measurement is performed at $0 \% \mathrm{RH}$ to simplify the analysis and remove water and constituent element peaks from the data. As expected, peaks appear at mass numbers 14, 28 and 29, indicating the presence of only nitrogen. This confirms that there is no discernible membrane degradation at $55^{\circ} \mathrm{C}$, and that the system is completely closed to air (discounting the possibility of the formation of carbonates in the presence of $\mathrm{CO}_{2}$ ).

Figure $8 \mathrm{~b}$, shows the mass spectrum when operated at $65^{\circ} \mathrm{C}$ at $0 \% \mathrm{RH}$ (after $30 \mathrm{mins}$ ); the presence of additional mass number peaks are observed and summarised in Table 1. 
Table 1 suggests possible element and hydrocarbon (side chain and/or backbone) fractures related to the mass numbers seen in Figure $8 \mathrm{~b}$; these correlate with the type of species expected for AAEM degradation products, as seen in Figures 1-3 and [21-24]. Whilst it is not possible to confirm the exact products without specific knowledge of the proprietary Tokuyama ionomer structure, the results clearly show the effect of operating at elevated temperature, and support the attribution of viscoelastic shifts seen on the QCM to ionomer degradation within the system. 


\section{Conclusions}

QCM analysis of AAEM thin films under accelerated thermal degradation conditions has been performed as a function of the relative humidity of the gas stream. Experimental results align with the theories proposed by Chempath et al. [17] and Macomber et al. [20], and suggest that humidity plays an important role in AAEM ionomer thermal degradation stability and that degradation can be minimised by ensuring a well hydrated membrane that is operating in the 'swelling' mode; however, thermal degradation cannot be entirely avoided. For this system, a $\mathrm{RH}$ above $\sim 66 \%$ shows reduced membrane degradation, corresponding to the point at which the ionomer is fully solvated.

\section{Acknowledgements}

The authors acknowledge the NPL for supporting Bharath's PhD Studentship and the EPSRC for funding the Electrochemical Innovation Lab's fuel cell research programme through (EP/M014371/1, EP/K038656/1; EP/G060991/1; EP/J001007/1; EP/I037024/1; EP/G030995/1; EP/G04483X/1). PRS acknowledges the Royal Academy of Engineering for funding support. 


\section{References}

[1] Jervis R, Mansor N, Gibbs C, Murray CA, Tang CC, Shearing PR, et al. Hydrogen Oxidation on PdIr/C Catalysts in Alkaline Media. J Electrochem Soc. 2014;161:F458-F63.

[2] Jervis R, Mansor N, Gibbs C, Murray CA, Tang CC, Brett DJL. Novel PdIr/C Catalysts for the Hydrogen Oxidation Reaction in Alkaline Media. Polymer Electrolyte Fuel Cells 13 (Pefc 13). 2013;58:637-50.

[3] Srinivasan S, Manko DJ, Koch H, Enayetullah MA, Appleby AJ. Recent Advances in Solid Polymer Electrolyte Fuel-Cell Technology with Low Platinum Loading Electrodes. J Power Sources. 1990;29:367-87.

[4] McLean GF, Niet T, Prince-Richard S, Djilali N. An assessment of alkaline fuel cell technology. Int J Hydrogen Energ. 2002;27:507-26.

[5] Varcoe JR, Slade RCT, Wright GL, Chen YL. Steady-state dc and impedance investigations of H2/O-2 alkaline membrane fuel cells with commercial $\mathrm{Pt} / \mathrm{C}, \mathrm{Ag} / \mathrm{C}$, and $\mathrm{Au} / \mathrm{C}$ cathodes. J Phys Chem $\mathrm{B}$. 2006;110:21041-9.

[6] Grew KN, Chiu WKS. A Dusty Fluid Model for Predicting Hydroxyl Anion Conductivity in Alkaline Anion Exchange Membranes. Journal of The Electrochemical Society. 2010;157:B327-B37.

[7] Li YS, Zhao TS. Understanding the performance degradation of anion-exchange membrane direct ethanol fuel cells. Int J Hydrogen Energ. 2012;37:4413-21.

[8] An L, Zhao TS, Wu QX, Zeng L. Comparison of different types of membrane in alkaline direct ethanol fuel cells. Int J Hydrogen Energ. 2012;37:14536-42.

[9] Karas F, Hnat J, Paidar M, Schauer J, Bouzek K. Determination of the ion-exchange capacity of anion-selective membranes. Int J Hydrogen Energ. 2014;39:5054-62.

[10] Gu S, Cai R, Luo T, Chen ZW, Sun MW, Liu Y, et al. A Soluble and Highly Conductive lonomer for High-Performance Hydroxide Exchange Membrane Fuel Cells. Angew Chem Int Edit. 2009;48:6499502.

[11] Bauer B, Strathmann H, Effenberger F. Anion-Exchange Membranes with Improved Alkaline Stability. Desalination. 1990;79:125-44.

[12] Varcoe JR, Slade RCT. Prospects for alkaline anion-exchange membranes in low temperature fuel cells. Fuel Cells. 2005;5:187-200.

[13] Varcoe JR, Atanassov P, Dekel DR, Herring AM, Hickner MA, Kohl PA, et al. Anion-exchange membranes in electrochemical energy systems. Energ Environ Sci. 2014;7:3135-91.

[14] Chempath S, Boncella JM, Pratt LR, Henson N, Pivovar BS. Density Functional Theory Study of Degradation of Tetraalkylammonium Hydroxides. The Journal of Physical Chemistry C. 2010;114:11977-83.

[15] Zagorodni AA, Kotova DL, Selemenev VF. Infrared spectroscopy of ion exchange resins: chemical deterioration of the resins. React Funct Polym. 2002;53:157-71.

[16] Neagu V, Bunia I, Plesca I. Ionic polymers - VI. Chemical stability of strong base anion exchangers in aggressive media. Polym Degrad Stabil. 2000;70:463-8.

[17] Chempath S, Einsla BR, Pratt LR, Macomber CS, Boncella JM, Rau JA, et al. Mechanism of tetraalkylammonium headgroup degradation in alkaline fuel cell membranes. J Phys Chem C. 2008;112:3179-82.

[18] Komkova EN, Stamatialis DF, Strathmann H, Wessling M. Anion-exchange membranes containing diamines: preparation and stability in alkaline solution. J Membrane Sci. 2004;244:25-34.

[19] Musker WK. Nitrogen Ylides from Tetramethylammonium Salts. J Chem Educ. 1968;45:200-\&.

[20] Macomber CS, Boncella JM, Pivovar BS, Rau JA. Decomposition pathways of an alkaline fuel cell membrane material component via evolved gas analysis. J Therm Anal Calorim. 2008;93:225-9.

[21] Arges CG, Ramani V. Two-dimensional NMR spectroscopy reveals cation-triggered backbone degradation in polysulfone-based anion exchange membranes. P Natl Acad Sci USA. 2013;110:24905.

[22] Arges CG, Wang LH, Parrondo J, Ramani V. Best Practices for Investigating Anion Exchange Membrane Suitability for Alkaline Electrochemical Devices: Case Study Using Quaternary Ammonium 
Poly(2,6-dimethyl 1,4-phenylene)oxide Anion Exchange Membranes. J Electrochem Soc.

2013;160:F1258-F74.

[23] Chen DY, Hickner MA. Degradation of Imidazolium- and Quaternary Ammonium-Functionalized Poly(fluorenyl ether ketone sulfone) Anion Exchange Membranes. Acs Appl Mater Inter.

2012;4:5775-81.

[24] Mohanty AD, Tignor SE, Krause JA, Choe YK, Bae C. Systematic Alkaline Stability Study of Polymer Backbones for Anion Exchange Membrane Applications. Macromolecules. 2016;49:3361-72. [25] Bharath VJ, Millichamp J, Neville TP, Mason TJ, Shearing PR, Brown RJC, et al. Measurement of water uptake in thin-film Nafion and anion alkaline exchange membranes using the quartz crystal microbalance. J Membrane Sci. 2016;497:229-38.

[26] Li YS, Zhao TS, Yang WW. Measurements of water uptake and transport properties in anionexchange membranes. Int J Hydrogen Energ. 2010;35:5656-65.

[27] B.R. Einsla SC, L.R. Pratt, J.M. Boncella, J. Rau, C. Macomber and B.S. Pivovar Stability of Cations for Anion Exchange Membrane Fuel Cells Ecs Transactions. 2007;11:1173-80.

[28] Liu G, Zhang G. QCM-D studies on polymer behavior at interfaces. New York: Springer; 2013.

[29] Kongkanand A. Interfacial Water Transport Measurements in Nafion Thin Films Using a QuartzCrystal Microbalance. J Phys Chem C. 2011;115:11318-25.

[30] John J, Hugar KM, Rivera-Melendez J, Kostalik HA, Rus ED, Wang HS, et al. An Electrochemical Quartz Crystal Microbalance Study of a Prospective Alkaline Anion Exchange Membrane Material for Fuel Cells: Anion Exchange Dynamics and Membrane Swelling. J Am Chem Soc. 2014;136:5309-22.

[31] Diaz LA, Abuin GC, Corti HR. Methanol sorption and permeability in Nafion and acid-doped PBI and ABPBI membranes. J Membrane Sci. 2012;411:35-44.

[32] Buttry DA, Ward MD. Measurement of Interfacial Processes at Electrode Surfaces with the Electrochemical Quartz Crystal Microbalance. Chem Rev. 1992;92:1355-79.

[33] Sauerbrey G. Verwendung Von Schwingquarzen Zur Wagung Dunner Schichten Und Zur Mikrowagung. Z Phys. 1959;155:206-22.

[34] Rodahl M, Hook F, Krozer A, Brzezinski P, Kasemo B. Quartz-Crystal Microbalance Setup for Frequency and Q-Factor Measurements in Gaseous and Liquid Environments. Rev Sci Instrum. 1995;66:3924-30.

[35] Cao-Paz A, Rodriguez-Pardo L, Farina J. Temperature compensation of QCM sensors in liquid media. Sensor Actuat B-Chem. 2014;193:78-81.

[36] Martin SJ, Granstaff VE, Frye GC. Characterization of a Quartz Crystal Microbalance with Simultaneous Mass and Liquid Loading. Anal Chem. 1991;63:2272-81.

[37] Vanysek P, Delia LA. Impedance characterization of a quartz crystal microbalance. Electroanal. 2006;18:371-7.

[38] Cady WG. Piezoelectricity; an introduction to the theory and applications of electromechanical phenomena in crystals. New rev. ed. New York,: Dover Publications; 1964.

[39] Merle G, Wessling M, Nijmeijer K. Anion exchange membranes for alkaline fuel cells: A review. J Membrane Sci. 2011;377:1-35.

[40] Vega JA, Mustain WE. Effect of $\mathrm{CO} 2, \mathrm{HCO}$ - and $\mathrm{CO} 3-2$ on oxygen reduction in anion exchange membrane fuel cells. Electrochim Acta. 2010;55:1638-44.

[41] Yanagi H, Fukuta K. Anion Exchange Membrane and lonomer for Alkaline Membrane Fuel Cells (AMFCs). Proton Exchange Membrane Fuel Cells 8, Pts 1 and 2. 2008;16:257-62.

[42] Abuin GC, Fuertes MC, Corti HR. Substrate effect on the swelling and water sorption of Nafion nanomembranes. J Membrane Sci. 2013;428:507-15.

[43] Abuin GC, Nonjola P, Franceschini EA, Izraelevitch FH, Mathe MK, Corti HR. Characterization of an anionic-exchange membranes for direct methanol alkaline fuel cells. Int J Hydrogen Energ.

2010;35:5849-54.

[44] Gierke TD, Munn GE, Wilson FC. The Morphology in Nafion Perfluorinated Membrane Products, as Determined by Wide-Angle and Small-Angle X-Ray Studies. J Polym Sci Pol Phys. 1981;19:1687704. 


\section{Captions:}

Figure 1: Hofmann (E2) elimination reaction mechanism.

Figure 2: Direct nucleophilic degradation, Pathway 1

Figure 3: Direct nucleophilic degradation, Pathway 2

Figure 4: Modified Butterworth Van Dyke equivalent circuit (where $L_{x}, C_{x}$ and $R_{x}$ are electrical analogies of electromechanical properties of the composite resonator $[16,24])$.

Figure 5: Experimental rig set-up. The inset figure on the bottom left shows the variable humidification chamber (fabricated in-house) in which the QCM is located.

Figure 6: CAS results for water uptake of the Tokuyama AS-4 membrane showing the effect of relative humidity on the composite resonator's series resonant frequency, adapted from our previously published work [16] (lines added as a guide to the eye). The inset image shows the raw Bode plot data.

Figure 7: The composite resonator's percentage shift in $R_{2}$ (representing the viscoelastic change in the film) when operating before and after exposure to elevated temperatures as a function of relative humidity.

Figure 8: In-line mass spectrometry data for the composite resonator operating at: a) $55^{\circ} \mathrm{C}$ (inset shows the full relative intensity scale) and b) $65^{\circ} \mathrm{C}$. (the results presented here are taken at $0 \% \mathrm{RH}$ )

Table 1: Mass number peaks registered in Figure $8 b$ when the composite resonator is operating at $65^{\circ} \mathrm{C}$ and suggested corresponding elements and hydrocarbon fractures. 